\title{
Digital Services for Industry 4.0: Assessing Collaborative Technology Readiness
}

DOI:

https://doi.org/10.1007/978-3-030-44322-1_45

\section{Document Version}

Accepted author manuscript

Link to publication record in Manchester Research Explorer

\section{Citation for published version (APA):}

Ramzan, A., Cisneros Cabrera, S., Sampaio, P., Mehandjiev, N., \& Kazantsev, N. (Accepted/In press). Digital Services for Industry 4.0: Assessing Collaborative Technology Readiness. Paper presented at 16th European, Mediterranean \& Middle Eastern Conference on Information Systems, Dubai, United Arab Emirates. https://doi.org/10.1007/978-3-030-44322-1_45

\section{Citing this paper}

Please note that where the full-text provided on Manchester Research Explorer is the Author Accepted Manuscript or Proof version this may differ from the final Published version. If citing, it is advised that you check and use the publisher's definitive version.

\section{General rights}

Copyright and moral rights for the publications made accessible in the Research Explorer are retained by the authors and/or other copyright owners and it is a condition of accessing publications that users recognise and abide by the legal requirements associated with these rights.

\section{Takedown policy}

If you believe that this document breaches copyright please refer to the University of Manchester's Takedown Procedures [http://man.ac.uk/04Y6Bo] or contact uml.scholarlycommunications@manchester.ac.uk providing relevant details, so we can investigate your claim.

\section{OPEN ACCESS}




\title{
Digital Services for Industry 4.0: Assessing Collaborative Technology Readiness
}

\author{
Asia Ramzan ${ }^{1}$, Sonia Cisneros-Cabrera ${ }^{1}$, Pedro Sampaio ${ }^{1}$, Nikolay Mehandjiev ${ }^{1}$ and \\ Nikolai Kazantsev ${ }^{1,2}$ \\ ${ }^{1}$ Alliance Manchester Business School, The University of Manchester, Manchester, United \\ Kingdom \\ \{asia.ramzan, sonia.cisneroscabrera, P.sampaio, \\ n.mehandjiev \} @manchester.ac.uk \\ 2 National Research University "Higher School of Economics", Moscow, Russia \\ nikolai.kazantsev@postgrad.manchester.ac.uk
}

\begin{abstract}
Collaborative technologies, such as peer-to-peer (P2P) communication systems, information sharing technologies, and online team meeting facilities have long been available to support the daily operation of businesses. We investigate how collaborative technologies can adapt to further underpin emerging business paradigms, namely the "Industry 4.0" trend. Our purpose is to contribute to the understanding of what characteristics would maintain a collaborative technology current and ready to be part of the digital services available to support the fourth industrial revolution demands. To fulfil this purpose, we propose a taxonomic solution for assessment of collaborative technologies readiness for Industry 4.0; the analysis obtained using this classification scheme serves as an indicator to elicitate what is required to be addressed to meet Industry 4.0 goals. We also present details about the taxonomy development and validation using a benchmarking approach. Finally, we exemplify how our taxonomy can be applied to assess a collaborative technology.
\end{abstract}

Keywords: digital services ' collaborative technologies ' Industry 4.0 . technology readiness.

\section{Introduction}

Industry 4.0 (I4.0) refers to an emerging trend which revolutionises the way manufacturing domains carry out their operations. I4.0 involves use of cyber-physical systems and transdisciplinary approaches to automate processes and enable services innovation fostering an agile business environment [1]-[3]. Approaches underpinning the I4.0 revolution include the digitalisation of processes to enable agility and costs reduction, new models of business collaborations and the development and implementation of Information and Communication Technologies (ICTs) to support operations [4], [5]. In these approaches, collaboration appears as a core enabler [6], [7]. Digital services supporting collaboration provide the process "glue" that enable cross-organizational links across the supply chains that are core to the I4.0 paradigm.

Despite recent advances in the understanding of enablers for I4.0 [8], [9], there are still limitations towards assessing processes, technology features, use cases, functional capabilities, standards, and data security features of current collaborative technologies. There is also limited guidance on how these technologies align with the I4.0 vision [5]. 
We contribute to bridging this gap by specifying what characteristics would enable a collaborative technology to support the operations of businesses towards the fourth industrial revolution, guided by the following research questions:

1. What are the key features and capabilities supported by collaborative technologies in the digital services domain?

2. What are the existing gaps in existing domain-specific collaborative technologies towards enabling the Industry 4.0 vision?

We present the specification of these key features and capabilities in a taxonomic solution that also enables the assessment of collaborative technologies readiness to support I4.0 goals and principles, such as interoperability, modularity, service orientation and information transparency [10]. The taxonomy proposed is applicable to available digital services which offer collaborative technologies in the form of applications, systems and tools, and is a first step towards the development of a comprehensive I4.0 digital services readiness assessment framework, focused on the collaborative technologies service offering.

The remainder of this paper is structured as follows: Section 2 presents the background information on collaborative technologies within digital services. Section 3 details the research method used for taxonomy development for collaborative technologies assessment. Section 4 presents the taxonomy developed, and Section 5 specifies the validation approach. Section 6 illustrates how to use the taxonomy with a sample of real-world domain-specific digital services with collaborative technologies functionalities. Finally, Section 7 presents conclusions and future directions of the research.

\section{Collaborative Technologies Overview}

The existing classification of collaborative technologies includes the division into two main categories: Horizontal and Vertical [7], [11]. Horizontal collaborative technologies usage includes personal, educational and business communications [11]. They can be further divided into four sub-categories: (1) peer-to-peer (P2P) communication systems, (2) social media tools, (3) information sharing and (4) team meeting support [11]. On the second classification, vertical collaborative technologies are relevant to a specific industry domain to which such digital services are specifically designed [11]; an example of this is the AirSupply ${ }^{1}$ Tool specifically supporting the aerospace industry by providing communication services that are secure and traceable between companies in the Aerospace supply chain. Another example is the FREIGHTQUOTE ${ }^{2}$ tool which is used mainly to support processes of logistics to reduce freight costs by optimisation approaches.

The number of users and industries also serve as criteria to differentiate vertical and horizontal collaborative technologies [7]. For example, a social media tool such as Twitter $^{3}$ can be considered a horizontal domain-independent digital communication technology used for broadcasting and one to one interactions for both personal and commercial purposes. In contrast, AirCollab ${ }^{4}$ is a domain-specific communication technology used for collaboration in the aerospace industry on a "many-to-many" approach.

Our work further classifies the collaborative technologies. We aim to systematise the variety of concepts through a taxonomy classification by unifying terminologies and characteristics of collaborative technologies into a single structure. As a basis for developing the initial structure of the taxonomy, we departed from the European Union's I4.0 vision articulated in the Horizon 2020 (H2020) vision document [12]. The next section presents the development of a taxonomy of collaborative technologies supporting I4.0 capabilities.

\footnotetext{
${ }^{1}$ https://www.boostaerospace.com/airsupply/

$2 \mathrm{https} / /$ www.freightquote.com/define/what-is-transportation-management-system-tms

${ }^{3}$ https://twitter.com

${ }^{4}$ http://www.boostaerospace.com/aircollab/
} 


\section{Taxonomy Development Methodology: Collaborative Technologies for Industry 4.0}

The taxonomy development method adopted for this research is based on Nickerson's method [13]. Nickerson et al. presented a comprehensive literature review of existing methods to develop a taxonomy in different domains; the method proposed focuses on taxonomy development applicable in Information Systems research (IS) based on the design science paradigm [14]. The method follows a three-level measurement model [15] with some modifications and also considers meta-characteristics and ending conditions for taxonomy development. Nickerson's method employs two approaches for the development of taxonomies: (1) inductive and (2) deductive. This approach also guides the logic for conceiving new dimensions or uses of collaborative technologies. The method also prescribes the interleaving application of inductive and deductive approaches, which we used for understanding and organising the concepts associated with the term "collaborative technology".

The steps followed in the development included the selection of a convenience sample of collaborative technologies available in the literature [14] from which we extracted its potential applications. We identified the characteristics of user interaction from the extracted applications (e.g. the application of collaborative technology for audio or video communications involves the user in audio and video conferencing). We also determined the multiplicity dimension of the features such as a sole company user and a group of companies of users who can have privileges to use the application. In this activity, we employed the deductive approach to ensure alternative perspectives were considered and represented in the taxonomy. For example, some collaborative technologies (e.g. Microsoft Lync $^{5}$ ) are designed to support general interactions between people.

In contrast, certain collaborative technologies (e.g. AirSupply) are developed for individuals who work for a given company. Similarly, some collaborative technologies cannot be used in certain locations of the world; for example, some countries have blocked Skype services due to security threats [16]. Our deductive approach, thus, leads us to identify the former feature as access rights of using the application and the latter feature as user location identification characteristics. In the following section, we present the taxonomy developed using this approach.

\section{$4 \quad$ The Industry 4.0 Collaborative Technologies Taxonomy}

The taxonomy depicted in Figure 1 illustrates the broad range of conceptual constructs to classify collaborative technologies offering digital services enabling I4.0. The key features and capabilities concepts present the novelty in the designed taxonomy; both supported in defining a concept of "collaborative technology". The designed taxonomy encompasses six major categories (i.e. Industries, Types, Uses, Applications, Features and Services) and many sub-categories. We start by presenting the different industries for which such digital service can be available, from the heavy machinery manufacturing industries, such as aerospace, railway and automotive domains, to healthcare industries. Secondly, we conceptualise the different roles a collaboration technology can take within an organisation, e.g. to support decision making, as an e-commerce platform, or to support e-learning. Next, we classify the concepts of horizontal and vertical collaborative technologies (see the details in Section 2), and also the different uses a collaborative technology can take: businessto-business (B2B), business-to-consumer (B2C) or consumer-to-consumer (C2C). In the fifth branch of the collaborative technologies taxonomy, we present the features that make a collaborative technology, which includes conferencing, screen-sharing, document-sharing, information-sharing, audio and video coordination, online communication, web browsing and multiple language support.

\footnotetext{
5 https://products.office.com/en-us/microsoft-lync-2013
} 


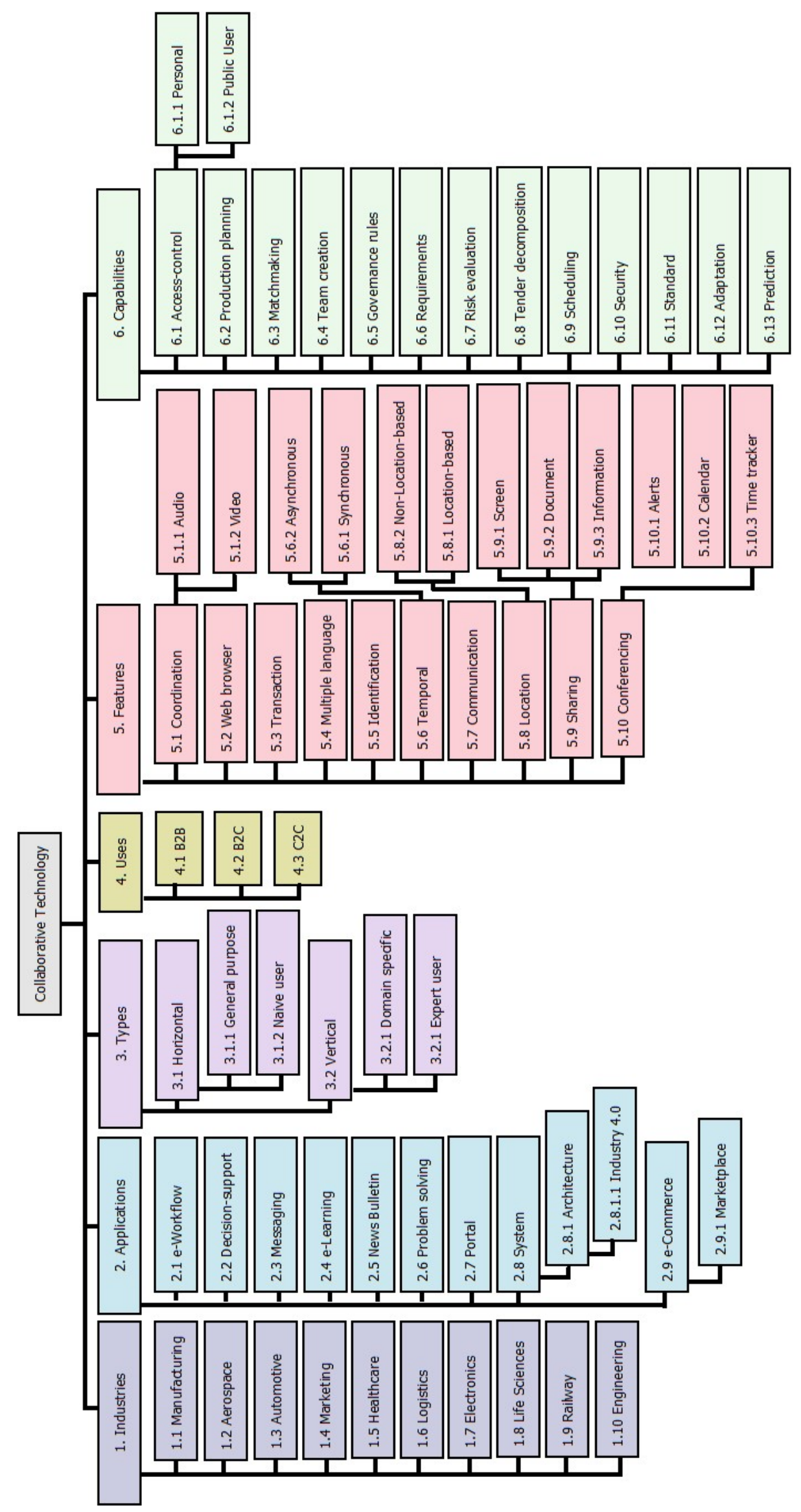

Fig. 1. Collaborative technology taxonomy towards Industry 4.0 support 
On the conferencing feature, for example, we consider the use of calendars for conferences or meetings, with invite features, reminders, and alert functionalities. The time tracker functionality, for example, helps to interact with others on an exact given time (e.g. a German user needs to consider the time zone of other users living in the United Kingdom while inviting to an online meeting). Finally, we present the core capabilities for I4.0 that a collaborative technology may present. These capabilities are access-control, production planning ${ }^{6}$, matchmaking ${ }^{7}$, team creation ${ }^{8}$, governance rules support, requirements analysis ${ }^{9}$, risk evaluation ${ }^{10}$, tender-decomposition ${ }^{11}$, scheduling, security, adaptation and predictions. In this branch, we also present the access control capability of the application, which determines that the services may be of use for business or personal purposes. Following this branch of core capabilities, we also have the production planning and scheduling capabilities to support the planning of the production and manufacturing materials and allocation of the resources. Also, the concept of matchmaking derives from the context of alliances, or business teams, where different companies or suppliers work together to achieve a goal where their selection is made based on some criteria and governance rules [17]. The risk evaluation, tender-decomposition security, adaptation and predictions capabilities are added to the taxonomy to test if a collaborative technology can support secure interoperability across the supply chain with the ability for adaptation [10]. These concepts were added to the taxonomy by employing the deductive approach, as specified in Section 3 above.

\section{$5 \quad$ Validation of Collaborative Technology Taxonomy}

There are various types of taxonomy validation techniques such as Delphi card sorting [18], orthogonality demonstration, utility demonstration, and benchmarking [19]. The Delphi card sorting is an in-person validating method, and the participants need to organise and label artefacts or concepts into relevant categories. A typical card-sorting exercise consists of four different states named planning, preparing, sorting and analysis. We have not employed this method due to limited resources. The orthogonality technique is used to extend the existing or base taxonomy by defining categories with clear classification criteria. The utility demonstration technique is also applicable to an extended taxonomy. We have not extended any taxonomy; therefore, both techniques are not suitable to validate our classification scheme.

We utilised benchmarking as an approach that also supports the comparison of taxonomies with other related classification structures. From the literature, we identified three taxonomical structures with a similar structure to our developed taxonomy: Mentzas, 1993 [20], Nickerson, 1997 [21] and Bafoutsou \& Mentzas, 2002 [22]; we compared our work with those. In the comparison, we found that the first classification structure [20] categorised group software in four different classes: (1) coordination model, (2) information sharing, (3) decision support and (4) organisational environment (user roles: centralised, decentralised). The second classification scheme [21] explored nine different categories, out of which two characteristics are similar to the ones in [20]. The "characteristics" category groups other six categories, and "application" category lists "workflow management" only. The third classification structure [22] organises collaborative systems in 24 different categories with 17 classes recognised as "characteristics". Four out of 17 categories were already present in the previous taxonomies, and 13 new categories were added as "characteristics". Figure 2 depicts the similarities found. Figure 3 presents the other seven similar categories identified as applications of collaborative technologies.

\footnotetext{
${ }^{6}$ Production planning service is used to plan products, materials and resources [23]

${ }^{7}$ Matchmaking is a service that provides suggestions of best potential partners for a given business opportunity [24]

${ }^{8}$ Team creation is a kind of temporary alliance that is developed for short-term to share skills or core competencies and resources in order to better respond to business opportunities [24], [25]

9 These are customers' requirement analysis that can be in the form of tracing individual customer order specification from the shop floor and monitoring their order execution and may involve forecasting item delivery and evaluating customer satisfaction [26]

${ }^{10}$ Risk evaluation is a process to compare the estimated risk against the given risk criteria [27]

${ }^{11}$ Tender-decomposition is a business opportunity that supports tenders breakdown into sub-tenders [28]
} 


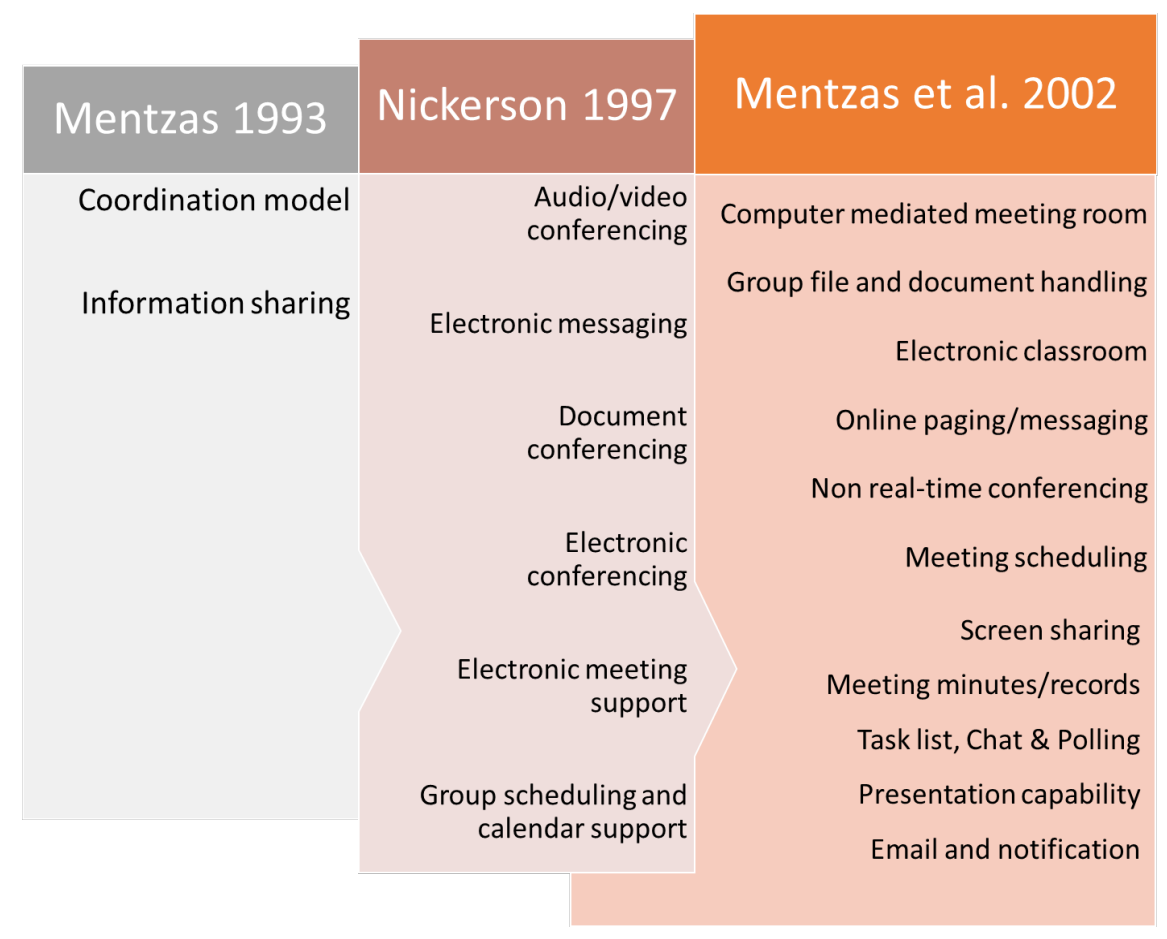

Fig. 2. Similar collaborative technology taxonomies - Characteristics

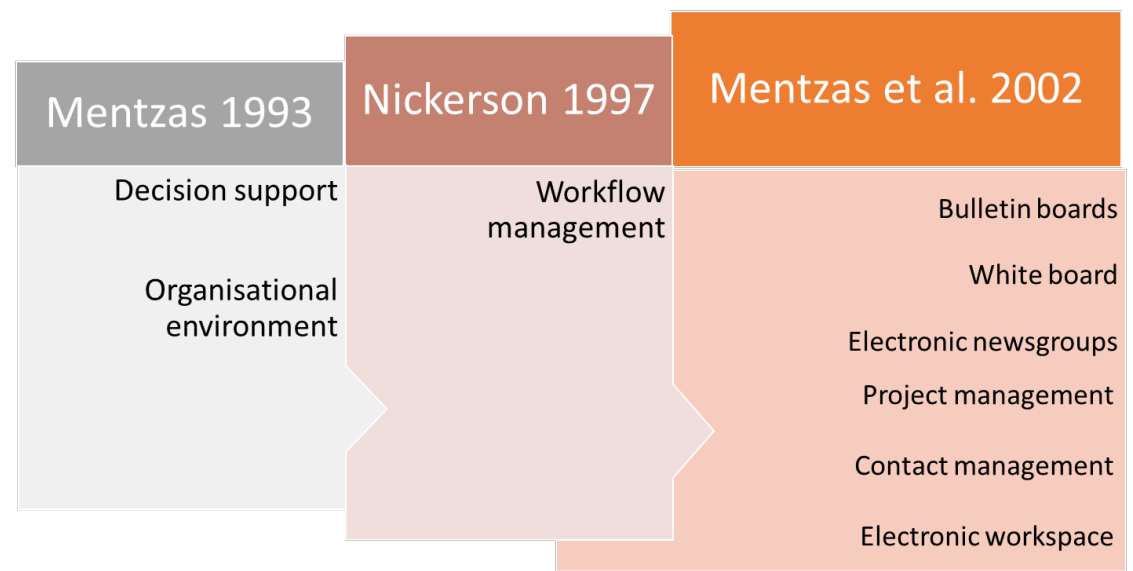

Fig. 3. Similar collaborative technology taxonomies - Applications

In the similarities identified, in comparison to the taxonomy we present in Figure 1, we found decision support, organisation environment and workflow management under applications category. Similarly, the bulletin boards, whiteboard, electronic newsgroups, project management, contact management and electronic workspace categories are recognised in the third classification structure [22] (see Figure 3). These previous alternative classification structures [20]-[22] also classified the artefacts in various applications (see Figure 4).

The analysis and comparison of these previous alternative classification structures with our developed classification scheme reveal that the main focus of these previous structures seems to be only on the horizontal collaborative technologies type. For example, we found nine different examples of horizontal collaborative technologies are listed such as Novell GroupWise, Lotus Notes, DataBean FarSite, Quarterdeck WebTalk, Intel ProShare, Silicon Graphics InPerson, Ventana GroupSytems, Campbell Services OnTime and FilesNet Visual WorkFlow [21]. And 47 different horizontal collaborative technologies such as CommonSpace, DocuTouch, TeamNow, DOLPHIN and CVW [22]. 
We developed a comprehensive, extensible and explanatory taxonomy which can accommodate future artefacts easily. We added the "types" artefact that has accommodated both horizontal and vertical collaborative technologies, and in future, a new type can also be listed under this category. Also, the "industries" category can accommodate more industries. We separated the application and characteristics categories in such a way it can differentiate that a collaborative technology has specific features for using some applications (e.g. decision making and problemsolving). The designed classification scheme also assists the user in the selection of a suitable tool by introducing the "uses" of an artefact which informs, for example, whether the tool should be designed for B2B or B2C activities.

The novelty in our developed taxonomy is the inclusion of the "capability" category that keeps unique artefacts which highlights the strength of the tool. For instance, tender-decomposition, machine-to-machine communication and VE creation services support to automatically execute the supply chain system and assist in creating a virtual enterprise to fulfil a task. These services indicate that the tool is suitable to execute the supply chain system of any organisation. Domain experts can add capabilities under this category associated with their specific domains such as inventory system, payroll system, or disease diagnosis system, to mention a few. Our developed taxonomy also covered the categories defined in the previous collaborative technology taxonomies (see [20]-[22]). In the next section, we present an analysis of some domain-specific collaborative technologies assessed utilising the concepts defined in the taxonomy presented in this paper.

\section{Assessing Collaborative Technologies: Representative Example}

In this section, we present an example of use for the taxonomy of collaborative technologies. We assessed 10 domain-specific collaborative applications. For our analysis, we selected the following platforms: BoostAerospace ${ }^{12}$, SAP $\mathrm{Ariba}^{13}$, SupplyOn ${ }^{14}$, KINAXIS ${ }^{15}$, Quintiq ${ }^{16}$, Generix group ${ }^{17}$, ARTS $^{18}$, iluster $^{19}$, Tradcloud $^{20}$ and Exostar ${ }^{21}$. The selection criteria included the consideration of digital services that offer collaborative technologies for supply chains and those which present information about their features, capabilities, functionalities and tools. These platforms were analysed with regards to their applications in supply chain system and capabilities to support an I4.0 solution utilising the collaborative technology taxonomy presented in Figure 1. Table 1 presents the results of the readiness assessment where the columns of the table represent the analysed domain-specific collaborative technology, and the rows of the table represent the information about the technologies' applications in different industries, features and capabilities, linked to Figure 1.

The analysis we carried out supports the identification that collaborative technologies are designed to facilitate supply chain systems of different industries but are not yet providing services (such as matchmaking and tender-decomposition) needed for an I4.0 support. Moreover, team selection and matchmaking services in these analysed tools have limited functionality and therefore provide only partial support. The collaborative team creation and governance services are also designed

\footnotetext{
12 .

$13 \mathrm{https}: / /$ www.ariba.com/

14 http://www.supplyon.com/

$15 \mathrm{http}: / / \mathrm{www} \cdot$ kinaxis.com/en/

$16 \mathrm{http://www.quintiq.com/}$

17 https://www.generixgroup.com/en

$18 \mathrm{https://www.arts.aero/references}$

19 https://valuechain.com/supply-chain-intelligence/iQluster/

$20 \mathrm{https}: / / \mathrm{www} \cdot$ tradecloud1.com/blog/topic/collaboration)

21 https://www.exostar.com/
} 
with limited functionalities in existing collaborative technologies consequently partially supported. For example, the Aircollab (a sub-system of Boostaerospace) platform has partial support in virtual collaboration of internal and external partners. Similarly, Boostaerospace has partial support in governance with founders, customers and service providers.

The majority of the analysed technologies do not have the capability to provide certain services (e.g. production planning and risk evaluation) and only a few tools provide full support, for example, the Quintiq platform renders full support to the production planning service, however, ARTS provides partial support and none of the other selected tools presents complete coverage regarding this service. Similarly, the KINAXIS tool supplies complete support in risk evaluation activity and SAP Ariba, SupplyOn and Exostar provide partial aid in this regard. The rest of the other six tools are not capable of measuring the risk against the given risk criteria. The management of the scheduling service has similar issues as production planning, and risk evaluation services have in the existing tools. Quintiq and Generix group fully helps in scheduling of resources and services involved in supply chain system; however, KINAXIS and iQluster have partial support and none of the rest of the tools has designed and managed such service.

Table 1. Existing collaborative technologies and their readiness to support Industry 4.0 Principles. The numbered items on the table are references to the categories and subcategories of the collaborative technologies taxonomy presented in Figure 1. The notation of the analysed technologies is as follows: BoostAerospace $=\mathrm{BA}$, SAP Ariba $=\mathrm{SA}$, SupplyOn $=\mathrm{SO}$, KINAXIS $=$ KX, Quintiq $=$ QN, Generix group $=$ GX, ARTS $=$ AS, iQluster $=\mathrm{iQ}$, Tradcloud $=$ $\mathrm{TC}$ and Exostar $=\mathrm{EX} . \boldsymbol{V}$ means the indicated characteristic is fully supported, $\mathrm{P}$ means partial support and X means the reviewed platform provides no support on the given characteristic.

\begin{tabular}{|c|c|c|c|c|c|c|c|c|c|c|c|c|c|}
\hline \multicolumn{14}{|c|}{ Analysed Collaborative Technologies } \\
\hline \multicolumn{4}{|l|}{ No. } & $\begin{array}{l}\text { B } \\
\mathbf{A}\end{array}$ & $\begin{array}{l}\text { S } \\
\mathbf{A}\end{array}$ & $\begin{array}{l}\mathbf{S} \\
\mathbf{O}\end{array}$ & $\begin{array}{l}\mathbf{K} \\
\mathbf{X}\end{array}$ & $\begin{array}{l}\mathbf{Q} \\
\mathbf{N}\end{array}$ & $\begin{array}{l}\mathbf{G} \\
\mathbf{X}\end{array}$ & $\begin{array}{l}\mathbf{A} \\
\mathbf{S}\end{array}$ & $\begin{array}{l}\mathbf{i} \\
\mathbf{Q}\end{array}$ & $\begin{array}{l}\text { T } \\
\text { C }\end{array}$ & $\begin{array}{l}\mathbf{E} \\
\mathbf{X}\end{array}$ \\
\hline \multirow{10}{*}{$\begin{array}{c}1 \\
\text { Indust } \\
\text { ries }\end{array}$} & \multicolumn{3}{|c|}{ 1.1 Manufacturing } & $\mathbf{X}$ & $\mathbf{X}$ & $\mathbf{X}$ & $\mathbf{X}$ & $\checkmark$ & $\mathbf{X}$ & $\mathbf{X}$ & $\checkmark$ & $\checkmark$ & $\checkmark$ \\
\hline & \multicolumn{3}{|c|}{ 1.2 Aerospace } & $\checkmark$ & $\checkmark$ & $\checkmark$ & $\checkmark$ & $\checkmark$ & $\mathbf{X}$ & $\checkmark$ & $\mathbf{X}$ & $\mathbf{X}$ & $\checkmark$ \\
\hline & \multicolumn{3}{|l|}{ 1.3 Automotive } & $\mathbf{X}$ & $\mathbf{X}$ & $\checkmark$ & $\checkmark$ & $\checkmark$ & $\mathbf{X}$ & $\checkmark$ & $\mathbf{X}$ & $\mathbf{X}$ & $\checkmark$ \\
\hline & \multicolumn{3}{|l|}{ 1.4 Marketing } & $\checkmark$ & $\checkmark$ & $\checkmark$ & $\checkmark$ & $\checkmark$ & $\checkmark$ & $\checkmark$ & $\checkmark$ & $\checkmark$ & $\checkmark$ \\
\hline & \multicolumn{3}{|l|}{ 1.5 Healthcare } & $\mathbf{X}$ & $\mathbf{X}$ & $\mathbf{X}$ & $\mathbf{X}$ & $\sqrt{ }$ & $\mathbf{X}$ & $\mathbf{X}$ & $\mathbf{X}$ & $\mathbf{X}$ & $\checkmark$ \\
\hline & \multicolumn{3}{|l|}{ 1.6 Logistics } & $\checkmark$ & $\checkmark$ & $\checkmark$ & $\checkmark$ & $\checkmark$ & $\checkmark$ & $\checkmark$ & $\checkmark$ & $\checkmark$ & $\checkmark$ \\
\hline & \multicolumn{3}{|l|}{ 1.7 Electronics } & $\mathbf{X}$ & $\mathbf{X}$ & $\mathbf{X}$ & $\checkmark$ & $\mathbf{X}$ & $\mathbf{X}$ & $\mathbf{X}$ & $\mathbf{X}$ & $\mathbf{X}$ & $\mathbf{X}$ \\
\hline & \multicolumn{3}{|l|}{ 1.8 Life Sciences } & $\mathbf{X}$ & $\mathbf{X}$ & $\mathbf{X}$ & $\checkmark$ & $\mathbf{X}$ & $\mathbf{X}$ & $\mathbf{X}$ & $\mathbf{X}$ & $\mathbf{X}$ & $\checkmark$ \\
\hline & \multicolumn{3}{|l|}{ 1.9 Railway } & $\mathbf{X}$ & $\mathbf{X}$ & $\checkmark$ & $\mathbf{X}$ & $\mathbf{X}$ & $\mathbf{X}$ & $\mathbf{X}$ & $\mathbf{X}$ & $\mathbf{X}$ & $\mathbf{X}$ \\
\hline & \multicolumn{3}{|l|}{ 1.10 Engineering } & $\mathbf{X}$ & $\mathbf{X}$ & $\checkmark$ & $\mathbf{X}$ & $\mathbf{X}$ & $\mathbf{X}$ & $\mathbf{X}$ & $\mathbf{X}$ & $\mathbf{X}$ & $\mathbf{X}$ \\
\hline \multirow{9}{*}{$\begin{array}{c}2 \\
\text { Appli } \\
\text { cation } \\
\text { s }\end{array}$} & \multicolumn{3}{|l|}{2.1 E-workflow } & $\mathbf{X}$ & $\mathbf{X}$ & $\mathbf{X}$ & $\mathbf{X}$ & $\mathbf{X}$ & $\mathbf{X}$ & $\mathbf{X}$ & $\mathbf{X}$ & $\mathbf{X}$ & $\mathbf{X}$ \\
\hline & \multicolumn{3}{|c|}{ 2.2 Decision-support } & $\mathbf{X}$ & $\mathbf{X}$ & $\mathbf{X}$ & $\mathbf{X}$ & $\mathbf{X}$ & $\mathbf{X}$ & $\mathbf{X}$ & $\mathbf{X}$ & $\mathbf{X}$ & $\mathbf{X}$ \\
\hline & \multicolumn{3}{|c|}{2.3 Messaging } & $\checkmark$ & $\checkmark$ & $\checkmark$ & $\checkmark$ & $\checkmark$ & $\checkmark$ & $\checkmark$ & $\checkmark$ & $\checkmark$ & $\checkmark$ \\
\hline & \multicolumn{3}{|l|}{ 2.4 E-learning } & $\mathbf{X}$ & $\mathbf{X}$ & $\mathbf{X}$ & $\mathbf{X}$ & $\mathbf{X}$ & $\mathbf{X}$ & $\mathbf{X}$ & $\mathbf{X}$ & $\mathbf{X}$ & $\mathbf{X}$ \\
\hline & \multicolumn{3}{|l|}{2.5 News bulletin } & $\checkmark$ & $\checkmark$ & $\checkmark$ & $\checkmark$ & $\checkmark$ & $\checkmark$ & $\checkmark$ & $\checkmark$ & $\checkmark$ & $\checkmark$ \\
\hline & \multicolumn{3}{|c|}{ 2.6 Problem-solving } & $\checkmark$ & $\sqrt{ }$ & $\sqrt{ }$ & $\sqrt{ }$ & $\checkmark$ & $\checkmark$ & $\sqrt{ }$ & $\checkmark$ & $\checkmark$ & $\checkmark$ \\
\hline & \multicolumn{3}{|c|}{2.7 Portal } & $\checkmark$ & $\checkmark$ & $\checkmark$ & $\checkmark$ & $\sqrt{ }$ & $\checkmark$ & $\sqrt{ }$ & $\checkmark$ & $\checkmark$ & $\checkmark$ \\
\hline & 2.8 System & $\begin{array}{l}2.8 .1 \\
\text { Architec } \\
\text { ture }\end{array}$ & $\begin{array}{l}2.8 .1 . \\
1 \\
\text { Indust } \\
\text { ry } 4.0\end{array}$ & $\mathbf{X}$ & $\mathbf{X}$ & $\checkmark$ & $\mathbf{X}$ & $\mathbf{X}$ & $\mathbf{X}$ & $\mathbf{X}$ & $\mathbf{X}$ & $\mathbf{X}$ & $\mathbf{X}$ \\
\hline & 2.9 e-Commerce & \multicolumn{2}{|c|}{ 2.9.1 Marketplace } & $\mathbf{X}$ & $\mathbf{X}$ & $\mathbf{X}$ & $\mathbf{X}$ & $\mathbf{X}$ & $\mathbf{P}$ & $\mathbf{X}$ & $\mathbf{X}$ & $\mathbf{X}$ & $\mathbf{X}$ \\
\hline \multirow{4}{*}{$\begin{array}{c}3 \\
\text { Types }\end{array}$} & \multirow[t]{2}{*}{ 3.1 Horizontal } & \multicolumn{2}{|c|}{$\begin{array}{l}\text { 3.1.1 General } \\
\text { purpose }\end{array}$} & $\mathbf{X}$ & $\bar{X}$ & $\bar{X}$ & $\bar{X}$ & $\bar{X}$ & $\bar{X}$ & $\bar{X}$ & $\mathbf{X}$ & $\mathbf{X}$ & $\mathbf{X}$ \\
\hline & & \multicolumn{2}{|c|}{ 3.1.2 Naïve user } & $\mathbf{X}$ & $\mathbf{X}$ & $\mathbf{X}$ & $\mathbf{X}$ & $\mathbf{X}$ & $\mathbf{X}$ & $\mathbf{X}$ & $\mathbf{X}$ & $\mathbf{X}$ & $\mathbf{X}$ \\
\hline & 3.2 Vertical & $\begin{array}{l}3.2 .1 \mathrm{Do} \\
\text { specific }\end{array}$ & & $\checkmark$ & $\checkmark$ & $\checkmark$ & $\checkmark$ & $\checkmark$ & $\checkmark$ & $\checkmark$ & $\checkmark$ & $\checkmark$ & $\checkmark$ \\
\hline & & $3.2 .2 \mathrm{Exl}$ & t user & $\checkmark$ & $\checkmark$ & $\checkmark$ & $\checkmark$ & $\checkmark$ & $\checkmark$ & $\checkmark$ & $\checkmark$ & $\checkmark$ & $\checkmark$ \\
\hline & 4.1 Business-to-b & hess & & $\checkmark$ & $\checkmark$ & $\checkmark$ & $\checkmark$ & $\checkmark$ & $\checkmark$ & $\checkmark$ & $\checkmark$ & $\checkmark$ & $\checkmark$ \\
\hline $\begin{array}{c}4 \\
\text { Uses }\end{array}$ & 4.2 Business-to-c & umer & & $\checkmark$ & $\checkmark$ & $\checkmark$ & $\checkmark$ & $\sqrt{ }$ & $\checkmark$ & $\checkmark$ & $\checkmark$ & $\checkmark$ & $\checkmark$ \\
\hline & 4.3 Consumer-to- & sumer & & $\mathbf{X}$ & $\mathbf{X}$ & $\mathbf{X}$ & $\mathbf{X}$ & $\mathbf{X}$ & $\mathbf{X}$ & $\mathbf{X}$ & $\mathbf{X}$ & $\mathbf{X}$ & $\mathbf{X}$ \\
\hline & 51 Coordination & $5.1 .1 \mathrm{Au}$ & & $\mathbf{X}$ & $\mathbf{X}$ & $\mathbf{X}$ & $\mathbf{X}$ & $\mathbf{X}$ & $\mathbf{X}$ & $\mathbf{X}$ & $\mathbf{X}$ & $\mathbf{X}$ & $\mathbf{X}$ \\
\hline 5 & 5.1 Coordınation & $5.1 .2 \mathrm{Vic}$ & & $\mathbf{X}$ & $\mathbf{X}$ & $\mathbf{X}$ & $\mathbf{X}$ & $\mathbf{X}$ & $\mathbf{X}$ & $\mathbf{X}$ & $\mathbf{X}$ & $\mathbf{X}$ & $\mathbf{X}$ \\
\hline $\begin{array}{c}\text { Featu } \\
\text { res }\end{array}$ & 5.2 Web browser & & & $\checkmark$ & $\checkmark$ & $\checkmark$ & $\sqrt{ }$ & $\checkmark$ & $\checkmark$ & $\checkmark$ & $\checkmark$ & $\checkmark$ & $\sqrt{ }$ \\
\hline & 5.3 Transaction & & & $\checkmark$ & $\checkmark$ & $\checkmark$ & $\checkmark$ & $\checkmark$ & $\checkmark$ & $\checkmark$ & $\checkmark$ & $\checkmark$ & $\checkmark$ \\
\hline
\end{tabular}




\begin{tabular}{|c|c|c|c|c|c|c|c|c|c|c|c|c|}
\hline \multicolumn{13}{|c|}{ Analysed Collaborative Technologies } \\
\hline \multicolumn{3}{|l|}{ No. } & B & $\begin{array}{l}\mathbf{S} \\
\mathbf{A}\end{array}$ & $\begin{array}{l}\mathrm{S} \\
\mathbf{O}\end{array}$ & $\mathbf{K}$ & $\begin{array}{l}\mathbf{Q} \\
\mathbf{N}\end{array}$ & $\begin{array}{l}\mathbf{G} \\
\mathbf{X}\end{array}$ & $\begin{array}{l}\mathbf{A} \\
\mathbf{S}\end{array}$ & $\begin{array}{l}\mathbf{i} \\
\mathbf{Q}\end{array}$ & $\begin{array}{l}\mathbf{T} \\
\mathbf{C}\end{array}$ & $\begin{array}{l}\mathbf{E} \\
\mathbf{X}\end{array}$ \\
\hline & \multicolumn{2}{|c|}{ 5.4 Multiple languages } & $\mathbf{X}$ & $\checkmark$ & $\checkmark$ & $\checkmark$ & $\mathbf{X}$ & $\checkmark$ & $\checkmark$ & $\mathbf{X}$ & $\mathbf{X}$ & $\mathbf{X}$ \\
\hline & \multicolumn{2}{|c|}{ 5.5 Identification } & $\sqrt{ }$ & $\checkmark$ & $\sqrt{ }$ & $\checkmark$ & $\checkmark$ & $\checkmark$ & $\checkmark$ & $\checkmark$ & $\checkmark$ & $\checkmark$ \\
\hline & \multirow[b]{2}{*}{ 5.6 Temporal } & 5.6.1 Synchronous & $\checkmark$ & $\checkmark$ & $\checkmark$ & $\checkmark$ & $\checkmark$ & $\checkmark$ & $\checkmark$ & $\checkmark$ & $\checkmark$ & $\sqrt{ }$ \\
\hline & & $\begin{array}{l}5.6 .2 \\
\text { Asynchronous }\end{array}$ & $\checkmark$ & $\checkmark$ & $\checkmark$ & $\checkmark$ & $\checkmark$ & $\checkmark$ & $\checkmark$ & $\checkmark$ & $\checkmark$ & $\checkmark$ \\
\hline & \multicolumn{2}{|l|}{ 5.7 Communication } & $\checkmark$ & $\checkmark$ & $\checkmark$ & $\checkmark$ & $\checkmark$ & $\checkmark$ & $\checkmark$ & $\checkmark$ & $\checkmark$ & $\checkmark$ \\
\hline & \multirow{2}{*}{5.8 Location } & $\begin{array}{l}\text { 5.8.1 Location- } \\
\text { based }\end{array}$ & $\checkmark$ & $\checkmark$ & $\checkmark$ & $\checkmark$ & $\checkmark$ & $\checkmark$ & $\checkmark$ & $\checkmark$ & $\sqrt{ }$ & $\sqrt{ }$ \\
\hline & & $\begin{array}{l}5.8 .2 \text { Non-location } \\
\text { based }\end{array}$ & $\checkmark$ & $\checkmark$ & $\checkmark$ & $\sqrt{ }$ & $\checkmark$ & $\checkmark$ & $\sqrt{ }$ & $\checkmark$ & $\checkmark$ & $\checkmark$ \\
\hline & \multirow{3}{*}{ 5.9 Sharing } & 5.9.1 Screen & $\mathbf{P}$ & $\mathbf{P}$ & $\mathbf{P}$ & $\mathbf{P}$ & $\mathbf{P}$ & $\mathbf{P}$ & $\mathbf{P}$ & $\mathbf{P}$ & $\mathbf{P}$ & $\mathbf{P}$ \\
\hline & & 5.9.2 Document & $\mathbf{P}$ & $\mathbf{P}$ & $\mathbf{P}$ & $\mathbf{P}$ & $\mathbf{P}$ & $\mathbf{P}$ & $\mathbf{P}$ & $\mathbf{P}$ & $\mathbf{P}$ & $\mathbf{P}$ \\
\hline & & 5.9.3 Information & $\mathbf{P}$ & $\mathbf{P}$ & $\mathbf{P}$ & $\mathbf{P}$ & $\mathbf{P}$ & $\mathbf{P}$ & $\mathbf{P}$ & $\mathbf{P}$ & $\mathbf{P}$ & $\mathbf{P}$ \\
\hline & \multirow{3}{*}{ 5.10 Conferencing } & 5.10.1 Alerts & $\mathbf{X}$ & $\mathbf{X}$ & $\mathbf{X}$ & $\mathbf{X}$ & $\mathbf{X}$ & $\mathbf{X}$ & $\mathbf{X}$ & $\mathbf{X}$ & $\mathbf{X}$ & $\mathbf{X}$ \\
\hline & & 5.10.2 Calendar & $\mathbf{X}$ & $\mathbf{X}$ & $\mathbf{X}$ & $\mathbf{X}$ & $\mathbf{X}$ & $\mathbf{X}$ & $\mathbf{X}$ & $\mathbf{X}$ & $\mathbf{X}$ & $\mathbf{X}$ \\
\hline & & $\begin{array}{l}\text { 5.10.3 Time } \\
\text { Tracker }\end{array}$ & $\mathbf{X}$ & $\mathbf{X}$ & $\mathbf{X}$ & $\mathbf{X}$ & $\mathbf{X}$ & $\mathbf{X}$ & $\mathbf{X}$ & $\mathbf{X}$ & $\mathbf{X}$ & $\mathbf{X}$ \\
\hline & \multicolumn{2}{|l|}{5.10 Conferencing } & $\checkmark$ & $\checkmark$ & $\checkmark$ & $\checkmark$ & $\checkmark$ & $\checkmark$ & $\checkmark$ & $\checkmark$ & $\checkmark$ & $\checkmark$ \\
\hline \multirow{14}{*}{$\begin{array}{c}6 \\
\text { Capa } \\
\text { bilitie } \\
\text { s }\end{array}$} & \multirow{2}{*}{ 6.1 Access control } & 6.1.1 Personal & $\mathbf{X}$ & $\mathbf{X}$ & $\mathbf{X}$ & $\mathbf{X}$ & $\mathbf{X}$ & $\mathbf{X}$ & $\mathbf{X}$ & $\mathbf{X}$ & $\mathbf{X}$ & $\mathbf{X}$ \\
\hline & & 6.1.2 Public & $\checkmark$ & $\checkmark$ & $\sqrt{ }$ & $\checkmark$ & $\sqrt{ }$ & $\checkmark$ & $\checkmark$ & $\checkmark$ & $\checkmark$ & $\checkmark$ \\
\hline & \multicolumn{2}{|c|}{6.2 Production planning } & $\mathbf{X}$ & $\mathbf{X}$ & $\mathbf{X}$ & $\mathbf{X}$ & $\sqrt{ }$ & $\mathbf{X}$ & $\mathbf{P}$ & $\mathbf{X}$ & $\mathbf{X}$ & $\mathbf{X}$ \\
\hline & \multicolumn{2}{|c|}{ 6.3 Matchmaking } & $\mathbf{X}$ & $\mathbf{X}$ & $\bar{X}$ & $\mathbf{X}$ & $\mathbf{X}$ & $\mathbf{X}$ & $\mathbf{X}$ & $\mathbf{X}$ & $\mathbf{X}$ & $\mathbf{X}$ \\
\hline & \multicolumn{2}{|l|}{$6.4 \mathrm{VE}$ creation } & $\mathbf{P}$ & $\mathbf{X}$ & $\mathbf{X}$ & $\mathbf{X}$ & $\mathbf{X}$ & $\mathbf{X}$ & $\mathbf{X}$ & $\mathbf{X}$ & $\mathbf{X}$ & $\mathbf{X}$ \\
\hline & \multicolumn{2}{|c|}{6.5 Governance rules } & $\mathbf{P}$ & $\mathbf{X}$ & $\mathbf{X}$ & $\mathbf{X}$ & $\mathbf{X}$ & $\mathbf{X}$ & $\mathbf{X}$ & $\mathbf{X}$ & $\mathbf{X}$ & $\mathbf{X}$ \\
\hline & \multicolumn{2}{|c|}{ 6.6 Requirements } & $\mathbf{P}$ & $\mathbf{P}$ & $\mathbf{P}$ & $\mathbf{P}$ & $\mathbf{P}$ & $\mathbf{P}$ & $\mathbf{P}$ & $\mathbf{P}$ & $\mathbf{P}$ & $\mathbf{P}$ \\
\hline & \multicolumn{2}{|c|}{ 6.7 Risk evaluation } & $\mathbf{X}$ & $\mathbf{P}$ & $\mathbf{P}$ & $\checkmark$ & $\mathbf{X}$ & $\mathbf{X}$ & $\mathbf{X}$ & $\mathbf{X}$ & $\mathbf{X}$ & $\mathbf{P}$ \\
\hline & \multicolumn{2}{|c|}{6.8 Tender decomposition } & $\mathbf{X}$ & $\mathbf{X}$ & $\mathbf{X}$ & $\mathbf{X}$ & $\mathbf{X}$ & $\mathbf{X}$ & $\mathbf{X}$ & $\mathbf{X}$ & $\mathbf{X}$ & $\mathbf{X}$ \\
\hline & \multicolumn{2}{|c|}{ 6.9 Scheduling } & $\mathbf{X}$ & $\mathbf{X}$ & $\mathbf{X}$ & $\mathbf{P}$ & $\sqrt{ }$ & $\sqrt{ }$ & $\mathbf{X}$ & $\mathbf{P}$ & $\mathbf{X}$ & $\mathbf{X}$ \\
\hline & \multicolumn{2}{|l|}{6.10 Security } & $\checkmark$ & $\checkmark$ & $\sqrt{ }$ & $\checkmark$ & $\sqrt{ }$ & $\checkmark$ & $\checkmark$ & $\checkmark$ & $\sqrt{ }$ & $\sqrt{ }$ \\
\hline & \multicolumn{2}{|l|}{ 6.11 Standard } & $\mathbf{X}$ & $\mathbf{X}$ & $\checkmark$ & $\mathbf{X}$ & $\mathbf{X}$ & $\mathbf{X}$ & $\mathbf{X}$ & $\mathbf{X}$ & $\mathbf{X}$ & $\mathbf{X}$ \\
\hline & \multirow{2}{*}{\multicolumn{2}{|c|}{ 6.12 Adaptation }} & $\mathbf{X}$ & $\mathbf{X}$ & $\mathbf{X}$ & $\mathbf{X}$ & $\mathbf{X}$ & $\mathbf{X}$ & $\mathbf{X}$ & $\mathbf{X}$ & $\mathbf{X}$ & $\mathbf{X}$ \\
\hline & & & $\mathbf{X}$ & $\mathbf{X}$ & $\mathbf{X}$ & $\mathbf{X}$ & $\mathbf{X}$ & $\mathbf{X}$ & $\mathbf{X}$ & $\mathbf{X}$ & $\mathbf{X}$ & $\mathbf{X}$ \\
\hline
\end{tabular}

All existing collaborative technologies are designed to connect and communicate with business communities, and customer requirements are dealt with by human experts which means that these systems are not capable of auto-analysing (parse, build internal representations and semantically understand) customer requirements and produce a workflow design accordingly. All analysed domain-specific collaborative technologies provide some level of support to communication, sharing, transaction execution, web-browsing, temporal and security features. However, remote conference calling is not possible with users needing to use ad-hoc applications for this purpose. For example, SupplyOn and Quintiq technology users use Webinar (a horizontal collaborative technology) for remote conferencing.

These analysed technologies are also used as bulletin boards to announce physical conferences, events and venues such as BoostAerospace used ISC (International Supplier Centre) Berlin and SAP Ariba conferences held at Las Vegas, Prague and Sydney in 2017 for customers and supplier's connections. Similarly, the sharing feature is partially implemented in all analysed digital services. These technologies support only information sharing where their users need to employ some other platforms for the documents and screen sharing. The adaptability, coordination, and predicting features are missing in all of the analysed collaborative technologies.

\section{Conclusions}

In this paper we specified key features and capabilities supported by collaborative technologies in the digital services arena and categorised them into a taxonomy of what forms a collaborative technology using Nickerson's methodology [13], particularly adding a category of capabilities that support the I4.0 goals. We identified the existing gaps in a sample of domain-specific collaborative technologies towards 
enabling the I4.0 vision utilising the taxonomy of collaborative technologies as an assessment tool. With this taxonomy, we contribute to the understanding of what characteristics collaborative technologies should address to support the fourth industrial revolution demands, and through its usage example, we presented a contribution to, for example, Research \& Development (R\&D) projects in the area of collaboration through technologies, where practitioners can utilise our taxonomy to systematically identify what characteristics should be developed towards an I4.0 project implementation. Finally, we also propose our work to be an initial step towards a more comprehensive I4.0 digital services readiness assessment framework.

Acknowledgements. The work presented has received funding from the European Commission under the European Union's Horizon 2020 research and innovation programme (grant agreement $n^{\circ}$ 723336). Financial support has been provided from the National Council of Science and Technology (abbreviated CONACYT) to Sonia Cisneros-Cabrera (agreement $\mathrm{n}^{\circ}$ 461338).

\section{References}

[1] D. P. F. Moller, "Digital Manufacturing/Industry 4.0," Springer International Publishing, 2016, pp. 307-375.

[2] T. D. Oesterreich and F. Teuteberg, "Understanding the implications of digitisation and automation in the context of Industry 4.0: A triangulation approach and elements of a research agenda for the construction industry," Comput. Ind., vol. 83, pp. 121-139, Dec. 2016.

[3] F. Almada-Lobo, "The Industry 4.0 revolution and the future of Manufacturing Execution Systems (MES)," J. Innov. Manag., 2015.

[4] S. Cisneros-Cabrera, A. Ramzan, P. Sampaio, and N. Mehandjiev, "Digital Marketplaces for Industry 4.0: A Survey and Gap Analysis," in Proceedings of 18th Working Conference on Virtual Enterprises, 2017.

[5] S. Heng, "Industry 4.0: Upgrading of Germany's Industrial Capabilities on the Horizon." 23-Apr-2014.

[6] L. M. Camarinha-Matos, R. Fornasiero, and H. Afsarmanesh, "Collaborative Networks as a Core Enabler of Industry 4.0," Springer, Cham, 2017, pp. 317.

[7] H.-P. Shih, K.-H. Lai, and T. C. E. Cheng, "Examining structural, perceptual, and attitudinal influences on the quality of information sharing in collaborative technology use."

[8] C. A. Havle and C. Ucler, "Enablers for Industry 4.0," in ISMSIT 2018 - 2nd International Symposium on Multidisciplinary Studies and Innovative Technologies, Proceedings, 2018.

[9] D. Trotta and P. Garengo, "Industry 4.0 key research topics: A bibliometric review," in 2018 7th International Conference on Industrial Technology and Management, ICITM 2018, 2018.

[10] M. Hermann, T. Pentek, and B. Otto, "Design Principles for Industrie 4.0 Scenarios," in 2016 49th Hawaii International Conference on System Sciences (HICSS), 2016, pp. 3928-3937.

[11] F. Erhun and O. Keskinocak, "Collaborative Supply Chain Management," in Planning Production and Inventories in the Extended Enterprise, K. Kempf, P. Keskinocak, and R. Uzsoy, Eds. Springer, Boston, MA, 2011, pp. 233-268.

[12] European Commission, "Digital Automation," Research \& Innovation Opportunities, 2015. [Online]. Available: http://ec.europa.eu/research/participants/portal/desktop/en/opportunities/h202 0/topics/fof-11-2016.html. [Accessed: 21-Nov-2018].

[13] R. C. Nickerson, U. Varshney, and J. Muntermann, "A Method for Taxonomy Development and its Application in Information Systems," Eur. J. Inf. Syst., 2013.

[14] S. Rummler and K. B. Ng, Collaborative Technologies and Applications for Interactive Information Design: Emerging Trends in User Experiences. 2009.

[15] K. D. Bailey, “A Three-level Measurement Model,” Qual. Quant., 1984. 
[16] E. Green, "What to do if Skype is blocked in your country | NordVPN," NordVPN, 2018. [Online]. Available: https://nordvpn.com/blog/why-is-skypeblocked-in-certain-countries/. [Accessed: 04-Nov-2019].

[17] S. A. Petersen, "Virtual enterprise formation and partner selection: an analysis using case studies," Int. J. Netw. Virtual Organ., vol. 4, no. 2, pp. 201-215, 2007.

[18] A. Soranzo and D. Cooksey, "Testing Taxonomies: Beyond Card Sorting," Bull. Assoc. Inf. Sci. Technol., 2015.

[19] M. Usman, R. Britto, J. Börstler, and E. Mendes, "Taxonomies in Software Engineering: A Systematic Mapping Study and a Revised Taxonomy Development Method," Information and Software Technology. pp. 43-59, 2017.

[20] G. N. Mentzas, "Coordination of Joint Tasks in Organizational Processes," $J$. Inf. Technol., 1993.

[21] R. C. Nickerson, "A Taxonomy of Collaborative Applications," Proc. $\{A I S\}$ 1997 Am. Conf. Inf. Syst., 1997.

[22] G. Bafoutsou and G. Mentzas, "Review and Functional Classification of Collaborative Systems," Int. J. Inf. Manage., 2002.

[23] F. Jiru and O. Harcuba, "Main Processes and their Requirements in the DigiCor Platform," 2017.

[24] N. Kazantsev, G. Pishchulov, N. Mehandjiev, and P. Sampaio, "Formation of demand-driven collaborations between suppliers in Industry 4.0 production networks," in 20th International Working Seminar on Production Economics, 2018, vol. 3, pp. 255-266.

[25] L. M. Camarinha-Matos and H. Afsarmanesh, "The Virtual Enterprise Concept," in Infrastructures for Virtual Enterprises. PRO-VE 1999. IFIP The International Federation for Information Processing, 1999, vol. 27, pp. 3-14.

[26] M. Maguire and N. Bevan, "User Requirements Analysis: A Review of Supporting Methods," Proc. IFIP 17th World Comput. Congr., 2002.

[27] A. Refsdal, B. Solhaug, and K. Stølen, "Risk Evaluation," in SpringerBriefs in Computer Science, 2015.

[28] S. Cisneros-Cabrera, P. Sampaio, and N. Mehandjiev, "A B2B team formation microservice for collaborative manufacturing in Industry 4.0," in 2018 IEEE World Congress on Services (SERVICES), 2018. 